\title{
İzmir İlindeki Üç Halk Pazarından Alınan Meyve ve Sebze Örneklerindeki Pestisit Kalıntı Miktarının Araştırılması*
}

\author{
Tutku KAYA, Atilla Levent TUNA ${ }^{* *}$ \\ Muğla Sitka Koçman Üniversitesi, Fen Fakültesi, Biyoloji Bölümü, Muğla, TÜRKIYE
}

\begin{tabular}{ll}
\hline \multicolumn{1}{c}{ Geliş Tarihi/Received: 27.06.2018 } & Kabul Tarihi/Accepted: 25.12 .2018 \\
\hline ORCID ID (Yazar sirasma göre / by author order) \\
\hline (Dorcid.org/0000-0003-3467-4567 (Dorcid.org/0000-0001-5123-0031 \\
"*Sorumlu Yazar/Corresponding Author: tuna@mu.edu.tr
\end{tabular}

*Sorumlu Yazar/Corresponding Author: tuna@mu.edu.tr

Öz: Bu çalıșmada; İzmir ili Buca, Bornova ve Karșıyaka halk pazarlarından rastgele toplanan toplam 42 adet meyve ve sebze [Asma yaprağ (Vitis vinifera), çilek (Fragaria ananassa), domates (Solanum lycopersicum), kiraz (Prunus avium), șeftali (Prunus persica), kabak (Cucurbita pepo), patlıcan (Solanum melongena), hıyar (Cucumis sativus), üzüm (Vitis vinifera), biber (Capsicum annuиm), patates (Solanum tuberosum), portakal (Citrus sinensis), nar (Punica granatum) ve limon (Citrus limon)] örneğinde yaygın olarak bulunan pestisit kalıntı düzeyleri araștırılmıștır. Numuneler; QuEChERS yöntemi ile ekstrakte edilmiş, LC-MS/MS ve GC/MS cihazlarında pestisit etken maddeleri belirlenmiştir. Analiz sonuçlarına göre; bulunan kalıntı miktarları Türk Gıda Kodeksi ve Avrupa Birliği maksimum kalıntı miktarı (Maximum residue levels, MRL)'na göre değerlendirilmiştir. Elde edilen sonuçlara göre, asma yaprağında bir fungisit türevi olan boscalid ve dimethomorph çok yüksek değerlerde çıkarken, myclobutanil ve penconazole sınır değere yakın çıkmıştır. Portakalda bir insektisit olan fenvalarate ve esfenvalarate türevleri yüksek değerlerde çıkmıștır. Limonda ise insektisit olan chlorpyrifos, cypermethrin ve pyriproxyfen türevleri yüksek değerlerde gözlenip, fenvalarate ve esfenvalarate türevleri ise sınır değerlere yakın bulunmuştur. Diğer numunelerde pestisit değerleri limit düzeylerin altında kalmış, hatta gözlenmemiștir. İncelenen 42 örneğin 35 adedinde limit düzeylerin üzerinde pestisit kalıntısı bulunmamıştır.

Anahtar Kelimeler: İnsektisit, fungisit, tarım ürünleri, maksimum kalıntı miktarı

\section{Investigation of Pesticide Residue Levels in Fruit and Vegetables Collected from Three Farmers Market in İzmir Province}

\begin{abstract}
In this study, the total pesticide residue levels of 42 fruit and vegetable samples (grape leaves (Vitis vinifera), strawberry (Fragaria ananassa), tomato (Solanum lycopersicum), cherry (Prunus avium), peach (Prunus persica), zucchini (Cucurbita pepo), eggplant (Solanum melongena), cucumber (Cucumis sativus), grape (Vitis vinifera), pepper (Capsicum annuum), potato (Solanum tuberosum), orange (Citrus sinensis), pomegranate (Punica granatum) and lemon (Citrus limon) collected from Buca, Bornova and Karşıyaka farmers markets in İzmir province were investigated. The samples were extracted with QuEChERS method, and pesticide active substances were determined in LC-MS / MS and GC / MS instruments. According to the analysis results, the residue levels were evaluated according to Turkish Food Codex and EU MRLs. According to the results obtained, while boscalid and dimethomorph, a fungicide derivative in the grapevine leaf, were at very high values, the myclobutanil and penconazole were close to the limit values. Fenvalarate and esfenvalarate derivatives, which are insecticides in orange, were at high values. In lemon, insecticides chlorpyrifos, cypermethrin and pyriproxyfen were observed at high values, while fenvalarate and esfenvalarate were found near to border values. In other samples, pesticide values remained below the limit levels and were not even observed. There were no pesticide residues on 35 of the 42 samples examined.
\end{abstract}

Keywords: Insecticides, fungicides, agricultural products, maximum residue levels

\footnotetext{
": Bu çalışma; Muğla Sıtkı Koçman Üniversitesi, Fen Bilimleri Enstitüsü tarafından kabul edilen birinci yazara ait "İzmir İlindeki Üç Halk Pazarından Alınan Meyve ve Sebze Örneklerindeki Pestisit Kalıntı Miktarının Araștııılması” isimli Yüksek Lisans Tez çalıșmasından üretilmiștir.
} 


\section{Giriş}

Artan dünya nüfusunun beslenme ihtiyacinı karşılamak için entansif tarım faaliyetleri çerçevesinde, tarımsal üretimde verim ve kaliteyi arttırmaya yönelik tarımsal mücadele yöntemleri günümüzde yoğun olarak uygulamaya girmiştir. $\mathrm{Bu}$ yöntemlerin başında, yüksek etkiye sahip olan ve hızlı sonuç veren tarımsal mücadele preparatlarının (pestisitler) kullanıldığı kimyasal savaş gelir. Tarımsal mücadelede kimyasal savaş bilinçli ve kontrollü kullanıldığında ekonomiktir ve ürünü toksin salgılayan organizmalardan da koruyabilir.

Pestisit türevleri, yüksek kalitede tarımsal ürün elde etme, amaciyla kullanılmakta fakat kullanım miktarları maksimum kalıntı miktarı (Maximum residue levels, MRL) değerleri üzerine çıktığında, canlı sağlığını ve çevreyi olumsuz etkilemektedir. Pestisit kalıntısı araştırma çalışmaları bu kalıntıların miktarlarını bilimsel yöntemlerle ortaya koyar. Rutin olarak yapılan kalıntı çalışmaların yanı sıra bilimsel araştırmalar ile teyit edilen veriler, canlı ve çevre sağlığını koruma ve bilinçlendirmede çok önemlidir (Durmuşoğlu, 2007).

Dünya pestisit pazarının büyüklüğünün yaklaşık 45 milyar dolar, Türkiye pazarının ise yaklaşık 600 milyon dolar olduğu tahmin edilmektedir. Türkiye'de; 2003 y1lında bayilerin pestisit satışı 29 bin ton iken, 2012 yılında 52 bin ton olmuştur. Yine Türkiye'de 2003-2013 yılları arasında pestisit ithalatı ve imalatı düzenli bir artış kaydederek 2013 yılında 22.000 tona, imalat miktarı ise 37.000 tona yükselmiştir (Anonim, 2015). Dünyada tarımsal kimyasal pazarının $\%$ 41.5'ini herbisitler, bitki büyüme düzenleyicileri ve büyüme engelleyiciler, \% 27.1'ini insektisitler, $\%$ 21.5'ini fungusitler ve \% 9.9'unu ise diğer kimyasallar oluşturmaktadır (Chakravarty, 2015). Türkiye'de de pestisit pazarı da dünya pazarına paralellik göstermektedir (Anonim, 2018).

Pestisitlerin kullanımının getirdiği çevresel sorunlar ve insan sağlığı üzerindeki olumsuz etkileri, bilimsel araştırmalar ile kesin olarak ortaya konmuştur. Parathion-methyl, chlorpyriphos-ethyl ve endosulfan insan endokrin sistemini etkileme özelliğindedirler. Methamidophos'un klastojenik etkili (kromozomal mutasyon) olduğu, dithiocarbamate grubu fungisitlerden mancozeb, propineb, thiram ve maneb etken maddelerinin sağlı ve çevre açısından ciddi riskler taşıdığı rapor edilmiștir. Bu pestisitlerin insanlarda kanser yapicı risklerinin bulunmasının yanı sıra, endokrin ve sinir sistemi üzerinde olumsuz etkileri vardır. Ayrıca teratojenik (doğum kusuru) etkileri de olan fungisitlerdendir (Delen ve ark., 2005).

Pestisitler, bilinçli ve ölçülü kullanılmazlarsa tarım ürünlerinde pestisit kalıntısının sürekli bir problem haline gelmesi kaçınılmazdır. Dinçay ve Civelek (2017), turunçgil ekosistemlerinde insektisit kalıntılarını araştırdıkları çalışmalarında, 54 bahçeden toplam 198 insektisit etken maddesini test etmiş ve analiz sonuçlarına göre örneklerin \% 7.41'inin MRL değerlerini ortalama 1-20 ug $\mathrm{kg}^{-1}$ düzeyinde aştığını bildirmişılerdir. Çalışmada bulunan insektisitlerin \% 26'sının turunçgillerde ruhsatsız ve \% 22'sinin ise Türkiye'de kullanımı sonlandırılmış ve yasaklanmış insektisitler olduğu bildirilmiştir. Zengin ve Karaca (2017), sera domatesinde pestisit kalıntılarını araştırdıkları çalışmalarında inceledikleri 60 adet domates numunesinin \% 63'ünde pestisit kalıntısı miktarını tespit edilebilir değerlerde bulmamışlardır. Pestisit kalıntısı tespit edilen \% 37'lik kisımda ise bu pestisitlerin hiçbiri maksimum kalıntı limitlerini aşmamıştır. Tespit edilen pestisitler arasında en çok rastlanılan pestisit Imidacloprid olmuştur.

Tarım ürünlerinde pestisit kullanımının ilkeler dâhilinde yapılmaması çevre sağlığ problemlerinin yanı sıra, hedef organizmaların aktif maddeye karşı direnç geliştirmesine de neden olabileceğinden dolayı konu önem arz etmektedir. Bu çalışmada da, konu hakkında küçük te olsa bir farkındalık yaratmak amacıyla, İzmir ili halk pazarlarından toplanan tüketime yönelik yaş sebze ve meyvelerde pestisit kalıntı durumunun belirlenmesi hedeflenmiştir.

\section{Materyal ve Yöntem}

Araştırmanın materyalini teşkil eden yaş sebze ve meyve örnekleri; 2017 yılının ilkbahar, yaz ve sonbahar mevsimlerinde İzmir ili Bornova, Buca ve Karşıyaka ilçeleri halk pazaryerlerinden toplanmıştır. Her bir pazaryerinden satıcı tarafindan direkt olarak satışa sunulan tezgâhlardan rastgele olmak üzere yaklaşık olarak 1'er kg 7 farklı çeşit meyve ve 7 farklı çeşit sebze olmak üzere toplam 42 adet örnek alınmıştır (Tablo 1). Her meyve ve sebze örneği her üç pazar yerinden ayrı ayrı toplanmıştır. Alınan örnekler ayrı ayrı etiketlenmiş ve buz kalıplarıyla soğuk tutulacak şekilde numaralandirılıp paketlenerek özel bir pestisit kalıntı analiz laboratuvarına ulaştırılmıştır. Laboratuvarda çalışmanın olacağa zamana kadar $+18 \quad{ }^{\circ} \mathrm{C}$ 'de parçalanmadan bekletilmiştir. Her pazar yerinden alınan örnekler ayrı ayrı analiz edilmiş ve her etken madde için en yüksek çıkan değer (mg $\left.\mathrm{kg}^{-1}\right)$ esas alınarak değerlendirme yapılmıştır. 
Tablo 1. Meyve ve sebze örneklerin türü ve toplandı̆̆

\begin{tabular}{lc}
\hline Örneğin cinsi & Alındığ tarih \\
\hline Asma yaprağ1 (Vitis vinifera) & $10 / 05 / 2017$ \\
Çilek (Fragaria ananassa) & $10 / 05 / 2017$ \\
Domates (Solanum lycopersicum) & $23 / 08 / 2017$ \\
Kiraz (Prunus avium) & $12 / 07 / 2017$ \\
Şeftali (Prunus persica) & $12 / 07 / 2017$ \\
Kabak (Cucurbita pepo) & $12 / 07 / 2017$ \\
Patlican (Solanum melongena) & $12 / 07 / 2017$ \\
Hiyar (Cucumis sativus) & $12 / 07 / 2017$ \\
Üzüm (Vitis vinifera) & $23 / 08 / 2017$ \\
Biber (Capsicum annuum) & $23 / 08 / 2017$ \\
Patates (Solanum tuberosum) & $23 / 08 / 2017$ \\
Portakal (Citrus sinensis) & $28 / 10 / 2017$ \\
Nar (Punica granatum) & $28 / 10 / 2017$ \\
Limon (Citrus limon) & $28 / 10 / 2017$ \\
\hline
\end{tabular}

Analiz edilecek pestisit etken maddeleri belirlenirken, yörede üreticiler tarafından meyve ve sebzelerde siklikla kullanılan etken maddeler dikkate alınmıştır. Yaş meyve ve sebze örneklerinde LC-MS/MS ve GC-MS cihazlarında aranan pestisit etken maddeleri sayıs 300 adettir. Örneklerin ekstraksiyonunda EN 15662 QuEChERS (Quick, Easy, Cheap, Effective, Rugged and Safe) metodu kullanılmıştır. Analiz safhasında, laboratuvarda örneklerin sapları ve çürük kısımları ayrıldıktan sonra karıştırıcı/parçalayıcıda partikül boyutu 250 $\mu$ m'den küçük olacak şekilde homojenize edilmiştir. $\mathrm{MgSO}_{4}, \mathrm{NaCl}$, Sodyum sitrat dihidrat ve Sodyum hidrojen sitrat sesquihidrat içeren ekstraksiyon tuzları yönteme göre eklenerek, asitli ürünlere (limon) $600 \mu \mathrm{l}$ diğer ürün grupları için de $200 \mu \mathrm{NaOH}$ ilave edilmiştir. Daha sonra analiz yöntemine uygun olarak gereken işlemlerden sonra viallere alınan örneklerin en son olarak LCMS/MS ve GC-MS cihazlarına enjeksiyonları yapılarak pestisit kalıntı miktarları tespit edilmiştir (Lehotay, 2005).

Pestisit kalıntı miktarlarının yorumlanmasında Türk Gıda Kodeksi, Pestisitlerin Maksimum Kalıntı Yönetmeliği (Anonim, 2016) esas alınmıştır.

\section{Bulgular ve Tartışma}

Bornova, Karşıyaka ve Buca halk pazar yerlerinden direkt üretici tezgâhlarından toplanan meyve ve sebze örneklerinin pestisit kalıntı analiz sonuçları Tablo 2'de sunulmuştur. Nar, kabak, patlıcan, biber ve patates örneklerinin analizleri sonucuna göre ölçüm limiti düzeyinde pestisit kalıntısı tespit edilememiş ve Tablo 2'de bunlara yer verilmemiştir.

Analizlerin sonuçları değerlendirildiğinde, Türkiye'de yemeklik olarak oldukça yoğun kullanılan asma yaprağında bir fungisit türevi olan dimethomorph etken maddesi sınır değerinin 870 katı ve boscalid etken maddesi ise sınır değerinin 260 katı olarak bulunmuştur (Tablo 2). Bunun sebebi, ilaçların yarılanma ömründen önce tarım ürünü hasadı ihtimali veya kontrolsüz ilaçlanma işlemi yapılmış olmasıdır. Asma yaprağında diğer etken maddeler sınır değerinin altında ve sınır değerine yakındır.

Yaş tarım ürünlerinde pestisit kalıntısı problemi, son yıllarda artış gösteren başta kanser olmak üzere çeşitli sağlık problemleri ile birlikte anılır olmuş, farkındalık yaratılmış ve bilimsel çalışmalarla konu daha fazla araştırılır hale gelmiştir. Şensoy ve ark. (2017), yaş üzüm ve salamura asma yapraklarında pestisit kalıntı miktarlarının belirlenmesine yönelik çalışmalarında, 250 farklı pestisiti taramışlar ve sofralık üzümlerde örneklerin tamamında, 30 farklı pestisite ait kalıntı tespit edilmiş, hatta yasak olmasına rağmen kullanılmış pestisitlerin bulunduğu görülmüştür. Salamura asma yapraklarında ise ticari bir marka olarak marketlerde satışı yapılmakta olan bir örnek dışında, pestisit kalıntısına rastlanmamıştır. Asmada mildiyö etkenine karşı kullanılan Dimethomorph ve külleme için kullanılan Boscalid etken maddeleri bu çalışmada incelenen asma yaprağı örneklerinde limit değerlerin oldukça üzerinde bulunmuştur. Asma yaprağının yemeklik olarak yoğun olarak tüketildiği bölgelerde bu durum ciddi bir risk faktörüdür. Zira in vitro çalışmalar insan periferik kan lenfositlerinde Boscalid'in genotoksik ve sitotoksik, dimethomorfun ise klastojenik (kromozomal mutasyon) ve yüksek toksik potansiyelde olduğunu göstermiştir (Anonymous, 2018).

Yapılan bir çalışmada İzmir semt pazarlarından toplanan ve Salihli ve Turgutlu ilçelerinde üretilen 11 adet kuru üzüm örneğinin \% 27.27'si kalıntısız bulunurken, \% 72.73'ünün pestisitle bulaşık olduğu bildirilmiştir (Tatlı, 2006). Bir diğer araştırmanın bulgularına göre, üzüm örneğinde vinclozolin, procymidon, bromoproplate, trichlorfon, diazinon, methyl paration, malathion, chlorpyrifos-ethyl ve ethion insektisitleri limit değerler üzerinde bulunmuştur (Güngör ve ark. 2002). Tatlı (2006)'ya göre ise üzümde pestisit kalıntısı tespit edilebilir düzeydedir. Asma yaprağının Türkiye ve Yunanistan dışında ticari bir ürün olarak kullanılmaması nedeniyle, ilaç firmalarının asmada MRL değerleri için standardı yetersizdir. Avrupa Birliği (AB) ülkelerinde asma yaprağında kodeks değerlerinin belirlenmesiyle birlikte Türkiye'de de Gıda, Tarım ve Hayvancılık Bakanlığı da asma yapraklarında bulunmasına izin 
Tablo 2. Meyve ve sebze örneklerinin pestisit kalıntı analiz sonuçları

\begin{tabular}{|c|c|c|c|}
\hline Meyve/sebze örneği & Etken madde & Sinır değer $\left(\mathrm{mg} \mathrm{kg}^{-1}\right)$ & Bulunan değer $\left(\mathrm{mg} \mathrm{kg}^{-1}\right)$ \\
\hline \multirow{7}{*}{ Asma yaprağ1 } & Boscalid & 0.01 & 2.6 \\
\hline & Dimethomorph & 0.01 & 8.7 \\
\hline & Imidacloprid & 2 & 0.013 \\
\hline & Kresoxim-methyl & 15 & 0.41 \\
\hline & Myclobutanil & 0.02 & 0.015 \\
\hline & Triadimenol & 0.1 & 0.049 \\
\hline & Penconazole & 0.05 & 0.048 \\
\hline \multirow{9}{*}{ Çilek } & Cyprodinil & 5 & 0.046 \\
\hline & Penconazole & 0.5 & 0.052 \\
\hline & Boscalid & 6 & 0.46 \\
\hline & Bupirimate & 2 & 0.068 \\
\hline & Ethirimol & 0.2 & 0.018 \\
\hline & Imidacloprid & 0.5 & 0.11 \\
\hline & Pyraclostrobin & 1.5 & 0.073 \\
\hline & Etoxazole & 0.2 & 0.11 \\
\hline & Kresoxim-Methyl & 1.5 & 0.015 \\
\hline \multirow{7}{*}{ Domates } & Deltamethrin & 0.3 & 0.085 \\
\hline & Boscalid & 3 & 0.033 \\
\hline & Cyromazine & 0.6 & 0.011 \\
\hline & Azoxystrobin & 3 & 0.2 \\
\hline & Chlorantraniliprole & 0.6 & 0.024 \\
\hline & Hexythiazox & 0.5 & 0.02 \\
\hline & Pyrimethanil & 1 & 0.043 \\
\hline \multirow{6}{*}{ Kiraz } & Boscalid & 0.3 & 0.013 \\
\hline & Cyromazine & 2 & 0.017 \\
\hline & Carbendazim & 0.5 & 0.011 \\
\hline & Cypermethrin & 2 & 0.034 \\
\hline & Fluopyram & 1.5 & 0.015 \\
\hline & Thiacloprid & 0.5 & 0.014 \\
\hline \multirow{4}{*}{ Şeftali } & Chlorantraniliprole & 1 & 0.056 \\
\hline & Deltamenthrin & 0.1 & 0.021 \\
\hline & Spirodiclofen & 2 & 0.044 \\
\hline & Phosmet & 1 & 0.017 \\
\hline \multirow{4}{*}{ Hiyar } & Metalaxyl M & 0.5 & 0.033 \\
\hline & Chlorpyrifos & 0.05 & 0.004 \\
\hline & Acetamiprid & 0.3 & 0.01 \\
\hline & Thiamethoxam & 0.5 & 0.025 \\
\hline \multirow{14}{*}{ Üzüm } & Azoxystrobin & 2 & 0.07 \\
\hline & Cyhalothrin, Lambda & 0.2 & 0.048 \\
\hline & Imidacloprid & 1 & 0.065 \\
\hline & Iprodione & 20 & 1.4 \\
\hline & Fludioxonil & 5 & 0.068 \\
\hline & Fluopyram & 1.5 & 0.027 \\
\hline & Hexythiazox & 1 & 0.018 \\
\hline & Indoxacarb Sum & 2 & 0.021 \\
\hline & Metalaxyl M & 2 & 0.27 \\
\hline & Pyrimethanil & 5 & 0.29 \\
\hline & Cyprodinil & 3 & 0.027 \\
\hline & Methoxyfenozide & 1 & 0.085 \\
\hline & Tebuconazole & 0.5 & 0.017 \\
\hline & Triadimenol & 2 & 0.015 \\
\hline \multirow{4}{*}{ Portakal } & Malathion & 2 & 0.1 \\
\hline & Fenvalarate \& Esfenvalarate & 0.02 & 0.16 \\
\hline & Pyriproxyfen & 0.6 & 0.017 \\
\hline & Chlorpyrifos & 0.3 & 0.067 \\
\hline \multirow{6}{*}{ Limon } & Chlorpyrifos & 0.01 & 0.038 \\
\hline & Cypermethrin & 0.01 & 0.037 \\
\hline & Imazalil & 5 & 0.013 \\
\hline & Pyriproxyfen & 0.01 & 0.063 \\
\hline & Buprofezin & 1 & 0.048 \\
\hline & Fenvalarate \& Esfenvalarate & 0.02 & 0.013 \\
\hline
\end{tabular}


verilen MRL değerlerini açıklamıştır (Anonim, 2016). $\begin{array}{lrrr}\text { Yörede oldukça yoğun tüketilen bir } & \text { diğer } \\ \text { meyve } & \text { olan } & \text { portakalda } & \text { ise } \\ \text { Fenvalarate\&esfenvalarate } & \text { insektisit } & \text { etken }\end{array}$ maddesi sınır değerinin 8 kat üzerinde tespit edilmiştir. Limonda ise chlorpyrifos, cypermethrin ve pyriproxyfen insektisit etken maddelerinde sinır değerlerinin oldukça üzerinde birikimler tespit edilmiştir (Tablo 2). Turunçgil ekosistemlerinde entansif tarımın bir sonucu olarak meyvelerde pestisit kalıntısı bulunma olasılığı da artış kaydetmiştir. Konuyla ilgili önemli bir çalışma yürüten Dinçay ve Civelek (2017), Muğla-Ortaca Bölgesi'ndeki turunçgil ekosistemlerinde 54 numuneden 26 tanesinin uygun olmadiğ $\breve{1}_{1}$ yani numunelerin \% 48'inin tüketim yönünden riskli olduğu sonucuna varmışlardır. Çalışmalarında, en fazla kullanılan ilk beş insektisit arasında turunçgilde ruhsatsız olan Chlorpyrifos ethyl'in \% 35.2'lik kullanım oranı ile 3. sırada yer aldığını rapor etmişlerdir. Önemli ve çok tüketilen diğer bir turunçgil meyvesi olan limonda Azar ve Kıvan (2009), chlorpyrifos-ethyl, buprofezin, carbofuran, methidathion, bromopropylate, parathion-methyl, cypermethrin ve dicofol kalıntısı tespit etmiştir. Aynı araştırmada, örneklerin çoğunda yüksek oranda chlorpyrifos ethyl kalıntısı tespit edilmiş, diğer pestisitlerin kalıntıları MRL'nin altında bulunmuştur. $\mathrm{Bu}$ çalışmada ise (Tablo 2), buprofezin, imizalil, fenvalarate, esfenvalarate limit düzeyi altında bulunurken; chlorpyrifos, cypermethrin ve pyriproxyfen etken maddeleri limit değerler üzerinde bulunmuştur. Örneklerin uygulama ile hasat arasında geçmesi gereken süreden önce toplanması veya kontrolsüz ilaçlama yapılmış olma ihtimali mevcuttur.

Diğer meyve sebze örneklerinde ise yaygın olarak kullanılan pestisit etken maddeleri ölçüm limitleri düzeylerinde bulunmuştur (Tablo 2). Bunun nedeni, örneklerde ilaçlama yapılmaması veya önerilen dozlarda kontrollü ilaçlama uygulaması olabilir. Yörede yetiştiriciliği yapılan ve yoğun olarak tüketilen kiraz meyvesinde yapılan bir araştırmada ise, Durmuşoğlu ve Çelik (2001), diazinon, dichlorvos, fenithrothion, fenthion, malathion phosalone ve parathion-methyl kalıntılarını araştırmışlar ve sonuç olarak yine turunçgillerde olduğu gibi tolerans değerleri üzerinde pestisit kalıntısı belirlemişlerdir.

Sebzeler de entansif tarım uygulamalarından payını almış ve günümüzde yoğun tarımsal ilaca maruz kalmışlardır. Halkın yoğun tükettiği sebzelerde tarım ilacı kalıntılarını ortaya koymaya yönelik bilimsel yayınlar çoğu zaman dikkat çekmektedir. Örneğin, Konya yöresinde halkın tüketimine sunulan mahalli pazarlardan toplanan domates, biber ve patlican örneklerinde 203 adet pestisitin kalıntı düzeyleri LC-MS/MS ve GC-MS cihazlarında belirlenmiştir. Araştırmadan elde edilen bulgulara göre, bir domates örneğinde kullanımı tamamen yasak olan Oxamyl'in yaklaşı 7 kat, biber örneğinde iki farklı pestisitin (Ethion ve Triazophos) limit üstü bulunduğu, bir başka biber örneğinde de Benomyl-carbendazim'in limit değerinin üzerinde olduğu tespit edilmiştir. Aynı araştırmada 10 adet patlıcan numunesinde ise, kullanımı yasaklanmış Oxamyl'in yaklaşık 11 kat yüksek düzeyi belirlenmiştir (Ersoy ve ark., 2011a). Hiyarda yapılan bir araştırmada ise (Güngör ve ark., 2002), malathion, diazinon, methyl-parathion, dichlorovos, bromoproplate, endosulfan etken maddeleri açısından limit üstü değere rastlanılmamıştır. Yine Cönger ve ark. (2012), ise sebzelerde chlorpyriphos ve metalaxyl$\mathrm{m}+$ mancozeb pestisitlerinden chlorpyrifos dişında MRL'nin üzerinde kalıntı tespit edilmediğini rapor etmişlerdir. Bizim çalışmamızda ise, hıyarda metalaxyl m, chlorpyrifos, acetamiprid ile thiamethoxam etken maddeleri limit değerlerin altında bulunmuştur. Biber örneğinde, Güngör ve ark. (2002) tarafindan malathion, diazinon, methylparathion, dichlorovos, bromoproplate, endosülfan taranmış, limit üstü değere rastlanmamış; ancak methamidophos kalıntıları bulmuşlardır. Cönger ve ark. (2012), bazı sebze türlerinde cyprodinil+fludioxonil, acetamiprid ve chlorpyriphos bakımından MRL'nin üzerinde kalıntı tespit etmemişlerdir. Bizim çalışmamızda da çilek ve üzümde aynı etken maddeler sınır değerlerin oldukça altında bulunmuştur (Tablo 2). Çilek örneğinde Güngör ve ark. (2002), methamidophos kalıntıları bulurken, Tatlı (2006), pestisit kalıntısını tespit edilebilir düzeyde olduğunu rapor etmiştir. Ersoy ve ark. (2011b) ise, üzüm ve çilekte Chlorpyrifos kalıntısına rastlamıştır. Bizim çalışmamızda ise, cyprodinil, penconazole, boscalid, bupirimate, ethirimate, imidacloprid, pyraclostrobin, etoxazole, kresoximmethyl etken maddeleri açısından limit düzeylerinin oldukça altında kalıntıya rastlanmıştır (Tablo 2).

Avrupa Birliği sürecinde ulusal tüketimimizde pestisit kalıntısız gıda tüketmenin önemi insan ve çevre sağlığı açısından iyi bilinmelidir. Bir ülkenin bu konuya önem vermesinin göstergesi pestisit kalıntısı konusunda yapılan bilimsel çalışmaların sayısıyla doğru orantılı olabilir. Tiryaki (2016), konuyla ilgili derleme çalışmasında Türkiye'de pestisit kalıntıları konusunda yapılan 76 adet çalışmayı değerlendirmiştir. Araştırma ve proje sonuçlarının makaleye dönüşme sayısının az olduğunu ifade etmiş ve AB'ne girme sürecinde, 
pestisit kalıntısı konusundaki çalışmalara daha fazla önem verilmesi gerektiğini bildirmiştir. Tarımsal ürünlerin $\mathrm{AB}$ standartlarında kalıntı kapsaması da ihracat için önemli bir koşuldur. Kalıntı analiz laboratuvarlarının akredite olması ve sonuçların şeffaf olması da bir gerekliliktir. AB web veri tabanlarında bu hususun yakından takip edildiği de unutulmamalıdır.

\section{Sonuçlar}

Bu çalışmada, İzmir'deki üç pazaryerinden alınan yaş sebze ve meyve örneklerindeki olası pestisit kalıntısı araştırılmıştır. İncelenen toplam 42 adet yaş meyve ve sebze örneğinde kullanılan tarım ilaçları genelde benzerlik göstermektedir. Çalışmada, 42 adet örneğin 35'inde pestisit kalıntı problemi bulunmamıştır. $\mathrm{Bu}$, istenen ve özlenen bir durum olup, iyi tarım uygulamalarında ulaşılan sonuçlara eşdeğer bir tabloyu ortaya koymaktadır. Çalışmanın sonuçlarına bakarak İzmir'deki pazarlarda satılan meyve ve sebzelerin pestisit kalıntısı ile ilgili olarak kesin bir yargıya varmak mümkün değildir. Ancak bu çalışma ile İzmir'de küçük bir örnek oluşturulmuş ve anlık durum ortaya konmuştur.

Bilinçsiz pestisit kullanımın engellenmesi çevre ve canlı sağlığı açısından büyük önem arz etmektedir. Üreticiler eğitilerek bilinçlendirilmeleri gerekmektedir. $\mathrm{Bu}$ noktada çiftçi kayıt sistemleri daha yakından incelenmeli ve Tarım ve Hayvancılık Bakanlığı, üretici denetimlerini sıklaştırmalı ve danışmanlık hizmetleri daha fazla önem kazanmalıdır. Ayrıca tarım ilacı bayilik sistemi ciddi şekilde ele alınmalı, bu işi yapan kişiler eğitilmeli, denetlenmeli ve halen yürürlükte bulunan İyi Tarım Uygulamaları Yönetmeliği’ne işlevsellik kazandırılmalıdır.

\section{Teşekkür}

$\mathrm{Bu}$ çalışma; Muğla Sıtkı Koçman Üniversitesi, Bilimsel Araştırmalar Koordinasyon Birimi tarafindan "17/040" No'lu proje ile desteklenmiştir.

\section{Kaynaklar}

Anonim, 2015. Ülkemizde Zirai Mücadele Girdilerinin Değerlendirilmesi. Gıda, Tarım ve Hayvancılık Bakanlığı, Tarımsal Araştırmalar ve Politikalar Genel Müdürlüğü, Zirai Mücadele Merkez Araştırma Enstitüsü Müdürlüğü Yayınları, ISBN: 978-605-9175-33-3, Aralık 2015, Ankara.

Anonim, 2016. Türk Gida Kodeksi Pestisitlerin Maksimum Kalıntı Limitleri Yönetmeliği. Gıda, Tarım ve Hayvancılık Bakanlığı, Resmi Gazete, Say1: 29899 (Mükerrer).
Anonim, 2018. Bitki Koruma Ürünleri Veri Tabanı. T.C. Gıda Tarım ve Hayvancılık Bakanlığı, Bitki Koruma Ürünleri Daire Başkanlığg, (https:// bku.tarim.gov.tr.), (Erişim tarihi: 25.06.2018).

Anonymous, 2018. Toxnet, Toxicology Data Network. (https://toxnet.nlm.nih.gov/cgi-bin/sis/search/a?dbs+ hsdb:@term+@DOCNO+7499), (Erişim tarihi: 25.06.2018).

Azar, İ., Kıvan, M., 2009. Bursa'da pazardan alınan limonlarda bazı insektisit kalıntılarının belirlenmesi. Türkiye III. Bitki Koruma Kongresi, Van Yüzüncü Y1l Üniversitesi, Ziraat Fakültesi, Bitki Koruma Bölümü, Bildiri Özetleri, 15-18 Temmuz, Van, s.16.

Chakravarty, S., 2015. World Agrochemical and Pesticide Market to Grow 8.7\% annually from 2014 to 2018. (http:// www.marketresearchreports.com), (Erişim tarihi: 25.06.2018).

Cönger, E., Aksu, P., Yiğit, N., Dokumacı, S., Baloğlu, Z., Burçak, A.A., 2012. Bazı pestisitlerin sebzelerdeki kalıntı davranışlarının belirlenmesi üzerine çalışmalar. Bitki Koruma Bülteni, 52(3): 273-288.

Delen, N., Durmuşoğlu, E., Güncan, A., Güngör, N., Turgut, C., Burçak, A., 2005. Türkiye'de pestisit kullanımı, kalıntı ve organizmalarda duyarlılık azalışı sorunları. Türkiye Ziraat Mühendisliği VI. Teknik Kongresi, 3-7 Ocak, Ankara, s. 629-648.

Dinçay, O., Civelek, H.S., 2017. Muğla ili Ortaca Bölgesi turunçgil ekosistemlerindeki insektisit kalıntılarının belirlenmesi. Türkiye Entomoloji Bülteni, 7(1): 31-40.

Durmusoğlu, E., 2007. Kontrolsüz ve bilinçsiz pestisit kullanımının neden olduğu sorunlar ve çözüm önerileri. Hasad, 32(270): 32-36.

Durmuşoğlu, E., Çelik, C., 2001. Türkiye'de pestisit kalıntıları üzerindeki araştırmalar. Türkiye Entomoloji Dergisi, 25(1): 65-80.

Ersoy, N., Tatlı, Ö., Özcan, S., Evcil, E., Coşkun, L.Ş., Erdoğan, E., 2011a. LC-MS/MS ve GC-MS'le bazı sebze türlerinde pestisit kalıntılarının tespiti. Selçuk Tarım ve Gida Bilimleri Dergisi, 25(3): 79-85.

Ersoy, N., Tatl1, Ö., Özcan, S., Evcil, E., Coşkun, L.Ş., Erdoğan, E., Keskin, G., 2011b. Üzüm ve çilekte pestisit kalıntılarının LC-MS/MS ve GC-MS ile belirlenmesi. Selçuk Tarım ve Gıda Bilimleri Dergisi, 25(2): 70-80.

Güngör, T., Urkun, T., Er, E., 2002. Gıdalarda Katk1 Kalıntı ve Bulaşanların İzlenmesi. Bursa Gıda Kontrol Araştırma Enstitüsü Yayını, Bursa.

Lehotay, S.J., 2005. Quick, easy, cheap, effective, rugged, and safe approach for determining pesticide residues. Pesticide Protocols. In: J. L. Martínez Vidal and A. Garrido Frenich (Eds.), Methods in Biotechnology, Humana Press Inc., Totowa, NJ Vol. 19, pp. 239-261.

Şensoy, R.İ.G., Ersayar, L., Doğan, A., 2017. Van ilinde satılmakta olan yaş ve kuru üzümler ile salamura asma yapraklarında pestisit kalıntı miktarlarının belirlenmesi. Yüzüncü Yll Üniversitesi Tartm Bilimleri Dergisi, 27(3): 436-446. 
Tatlı, Ö., 2006. Ege Bölgesine özgü bazı yaş meyve, sebze ve kurutulmuş gida ürünlerinde pestisit kalıntı düzeylerinin tespiti. Yüksek Lisans Tezi, Çukurova Üniversitesi Fen Bilimleri Enstitüsü, Adana.

Tiryaki, O., 2016. Türkiye'de yapılan pestisit kalıntı analiz ve çalışmaları. Erciyes Üniversitesi Fen
Bilimleri Enstitüsü Dergisi, 32(1): 72-82.

Zengin, E, Karaca, İ., 2017. Uşak ilinde örtü altı üretimi yapılan domateslerdeki pestisit kalıntılarının belirlenmesi. Süleyman Demirel Üniversitesi Fen Bilimleri Enstitüsü Dergisi, 21(2): 554-559. 